\title{
Measuring Serum Uric Acid Level in Terms of Preanalytics for Public Health
}

\section{Nilgün Tekkesin}

Memorial Hospital, Biochemistry Laboratory, Istanbul, Turkey

Uric acid (UA) is the final product of purine catabolism. For many years, UA has been used in clinical practice as a marker of several metabolic disturbances, although until recently its antioxidant properties had not been considered. UA is the most abundant aqueous antioxidant in humans, and contributes as much as two-thirds of all free radical scavenging capacity in plasma. The plasma concentration of UA is almost 10-fold higher than other antioxidants, such as vitamin C and vitamin E [1]. Moreover, UA has much higher antioxidant capacity [2].It is particularly effective in quenching hydroxyl, superoxide and peroxynitrite radicals, and may serve a protective physiological role by preventing lipid peroxidation [3]. In a variety of organs and vascular beds, local UA concentrations increase during acute oxidative stress and ischaemia, and the increased concentrations might be a compensatory mechanism that confers protection against increased free radical activity [4].

Excess serum accumulation of UA defined as hyperuricemiacan lead to various diseases, and most notably UA is causally involved in the pathogenesis of gouty arthritis. Recently, gout has been linked to cardiovascular disease. Epidemiological data supports the strong association between cardiovascular disease and gout [57]. Also, a number of epidemiological reports have increasingly linked hyperuricemia with neurological diseases [8].UA can act as a prooxidant, particularly at increased concentrations, and may thus be a marker of oxidative stress [9], but it may also have a therapeutic role as an antioxidant [10].

UA's contribution to atherosclerotic vascular disease, however, is still somewhat controversial. Over recent years, increasing attention has been paid to its potential role in the disease manifestations that ensue. It is unclear whether high UA concentrations promote or protect against the development of cardiovascular disease, or simply act as a passive marker of increased risk. Despite the widely held view that elevated serum UA concentrations confer increased risk of atherosclerotic disease, there is no compelling biological evidence of a causal link. Free radical activity is characteristically increased in patients with any one of several major cardiovascular risk factors, and is thought to play a key role in the early development of atherosclerosis. Ongoing basic research is likely to shed new light on the cardiovascular effects of UA, and will hopefully allow the significance of serum concentrations to be interpreted more clearly.
Measurement of US might be a need in terms of preanalytics, The analyse is inexpensive and can be performed with simple methods in routine laboratories. Thus, it should be stated as a preventive, costeffective approach for public health. High-risk groups need to be studied in more detail, and a randomized controlled trial to test the effect of UA reduction on clinical end points may be warranted [9]. Patients with advanced atherosclerotic disease may present an even more attractive group, with a potentially larger benefit from intervention, than subjects from the general population. We might use uric acid as a new candidate to fascilate changes in therapy as developments in medicine are not always straightforward.

\section{References}

1. Becker BF (1993)Towards the physiological function of uric acid. Free Radic Biol Med14: 615-631.

2. Buettner GR (1993) The pecking order of free radicals and antioxidants: lipid peroxidation, a-tocopherol, and ascorbate. Arch BiochemBiophys 300: 535543

3. Squadrito GL, Cueto R, Splenser AE, Valavanidis A, Zhang H, et al. (2000) Reaction of uric acid with peroxynitrite and implications for the mechanism of neuroprotection by uric acid. Arch Biochem Biophys 376: 333-337.

4. Nieto FJ, Iribarren C, Gross MD, Comstock GW, Cutler RG (2000) Uric acid and serum antioxidant capacity: a reaction to atherosclerosis? Atherosclerosis 148: 131-139.

5. Abbott RD, Brand FN, Kannel WB, Castelli WP (1988) Gout and coronary heart disease: the Framingham Study. J ClinEpidemiol 41: 237-242.

6. Krishnan E, Svendsen K, Neaton JD, Grandits G, Kuller LH, et al. (2008) Longterm cardiovascular mortality among middle-aged men with gout. Arch Intern Med168:1104-1110.

7. Krishnan E, Baker JF, Furst DE, Schumacher HR (2006) Gout and the risk of acute myocardial infarction. Arthritis Rheum 54: 2688-2696.

8. Chamorro A, Obach V, Cervera A, Revilla M, Deulofeu R, et al. (2002) Prognostic significance of uric acid serum concentration in patients with acute ischemic stroke. Stroke 33:1048-1052.

9. Strazzullo P, Puig JG (2007) Uric acid and oxidative stress: relative impact on cardiovascular risk? Nutr Metab Cardiovasc Dis17:409-414.

10. Strasak AM, Rapp K, Hilbe W, Oberaigner W, Ruttmann E, et al. (2007) The role of serum uric acid as an antioxidant protecting against cancer: prospective study in more than 28000 older Austrian women. Ann Oncol18:1893-1897.

${ }^{*}$ Corresponding author: Nilgün Tekkesin, Memorial Hospital, Biochemistry Laboratory, Istanbul, Turkey, E-mail: niltek@hotmail.com

Received September 13, 2012; Accepted September 13, 2012; Published September 16, 2012

Citation: Tekkesin N (2012) Measuring Serum Uric Acid Level in Terms of Preanalytics for Public Health. Biochem Anal Biochem 1:e117. doi:10.4172/2161. $1009.1000 \mathrm{e} 117$

Copyright: (c) 2012 Tekkesin N. This is an open-access article distributed under the terms of the Creative Commons Attribution License, which permits unrestricted use, distribution, and reproduction in any medium, provided the original author and source are credited. 